\title{
STRATEGIC ROLE OF HAMPI DEVELOPMENT AUTHORITY IN PROMOTING TOURISM IN KARNATAKA: A STUDY
}

\author{
P. Pakkeerappa* \& Joby Thomas**
}

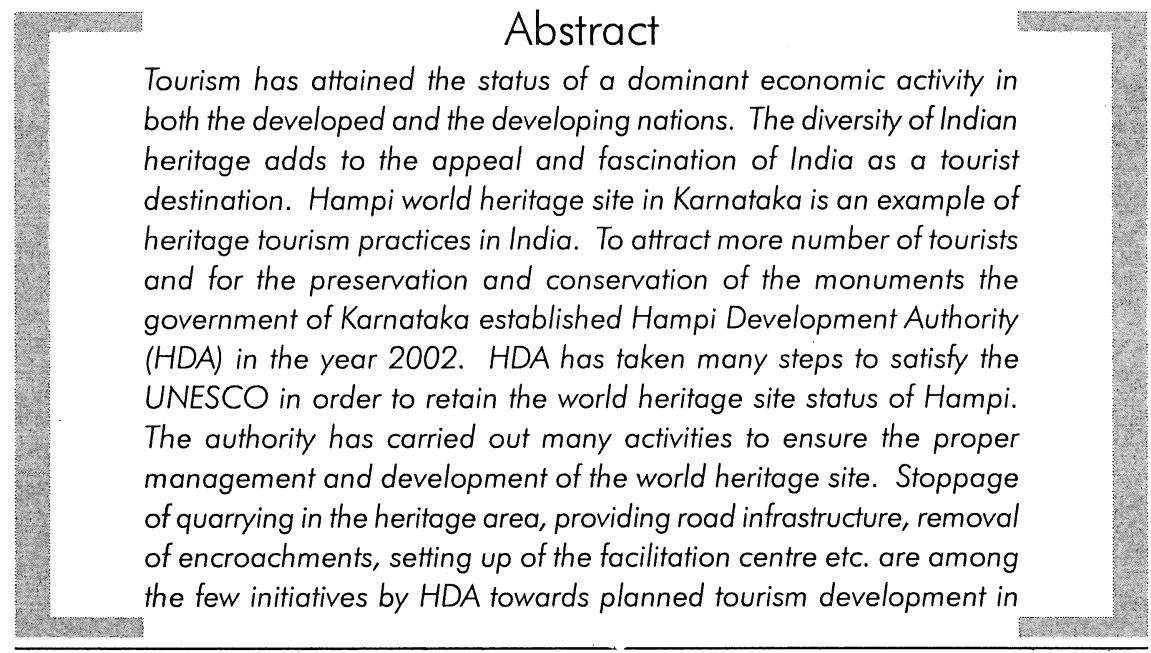

* Professor and Former Dean, Department of Business Administration, Mangalore University, Mangalagangotri, Karnataka.PIN-574 199.Email: ppkmba@yahoo.co.in

** Faculty, Department of Tourism Studies, Christ College, Bangalore 560029. E-mail: jobytourism@yahoo.co.in 

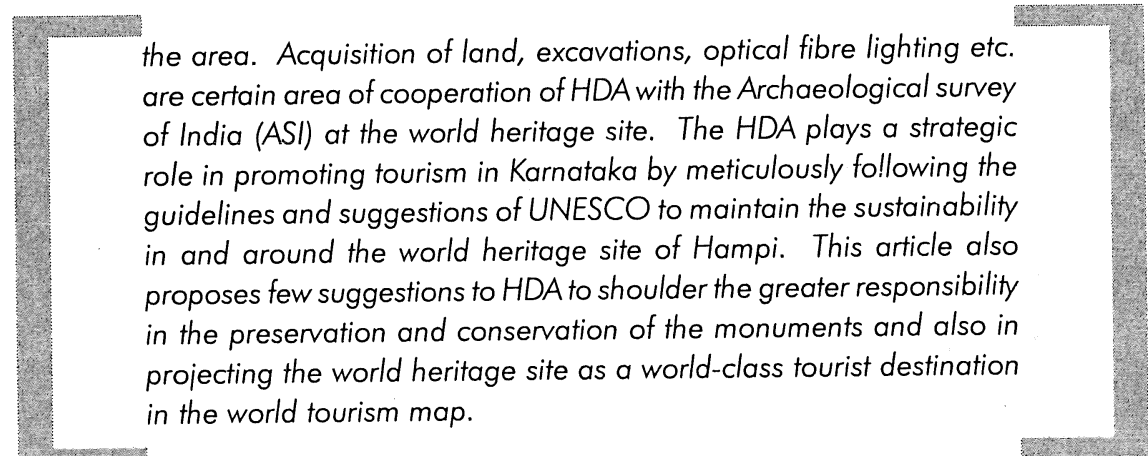

\section{Introduction}

Tourism is one of the fastest growing industries in the world and has emerged as a dominant economic activity in both the developed and developing nations. Tourism is geared up to promote cultural exchange and international cooperation across the nations. Today, it has been recognized as the largest source of foreign exchange for many countries. India is a land of diversity and is the reservoir of diverse cultures. Its civilization dates back to five thousand years and is the home for several languages, religions and cultures. The diversity of our heritage adds to much of its appeal and fascination as a tourist destination. The natural heritage is embodied in the Himalayan landscape while other forms of its cultural heritage are enshrined in its architecture.

Modern tourists expect variety and India is the land of contrasts, which provides a great potential to both domestic and international tourists. In the context of heritage preservation and conservation, the Indian culture always taught men to live and respect nature, seeing themselves as part of it. Karnataka is one among the Indian states bestowed with a lot of cultural resources. Now, tourism is recognized as the "Sunrise industry" of Karnataka. Nature and history have blessed this golden land with a wealth of attractions including the World Heritage Sites of Hampi and Pattadakal. Hampi alone could match the grandeur and mythical properties of stones of the world's wonders. These destinations are best examples for heritage tourism practices that are prevalent in India.

Hampi is on the banks of the river Tungabhadra in Bellary district of Karnataka. Worldwide, Hampi is famed for its significant monuments like legendary Stone Chariot. It is a place with vast sites of monuments and ruins that indicate an era of glories, triumphs and tragedies. Hampi is a destination attracting a large number of tourists from India and abroad. The arrival of foreign tourists has 
increased in the past few years. Hampi was included in the list of world Heritage sites in 1986. Without proper maintenance, it is not possible to attract more and more tourists. Realizing this, the State Government established Hampi Development Authority (HDA) for management of Hampi area and for the preservation and conservation of the monuments. Sensing the growing importance of Hampi in the world tourism and its potential as a tourist destination Hampi Development Authority is taking active interest in developing and maintaining this world class destination.

\section{Hampi Development Authority (HDA)}

Hampi Development Authority (HDA) has established for proper conservation of the monuments and sites and also develop the necessary tourist infrastructure at Hampi, the World Heritage site.

The Government of Karnataka in its G. O.No. SKD 97 KMU 98 (P II) issued on $21^{\text {st }}$ March, 2002 provided for the formation of Hampi World Heritage Area Management Authority under the Chairmanship of Deputy Commissioner, Bellary and state Level Advisory Committee under the Chairmanship of Honorable District Minister (in charge) of Bellary. This Authority is a creation of an executive order. The Hampi World Heritage Area Act was passed by the both houses of Legislature in 2002 and this is the first special Legislation of its kind brought out by any State in India.

\section{How HDA Works?}

The HDA plays a dominant role in the area management at Hampi. Authority's top priority is to attract more number of tourists and create better image in the minds of tourists about Hampi, as a world-class destination. HDA has plans to appoint a training agency to train suitable persons and ensure the availability of tourist guides to facilitate the tourists at Hampi. A Large number of tourists visit Hampi from both abroad and India. But at present the tourists find insufficient accommodation, misbehavior of local community and shortage of the trained guides at this destination.

In Hampi, we cannot find any recreational facilities for tourists coming from India or abroad. Apart from curiosity and knowledge an important purpose of visit to the destinations is leisure. The HDA has determined to establish exhibition centers in and around Hampi and also planned to develop gardens for beautifying the surroundings with the sole purpose of attracting more number of family 
visitors. The steps have already been taken by HDA to implement this Action Plan. Further, the Authority will set up bookshops, family restaurants and children's parks.

The security of the monuments and the premises in Hampi, of course is another priority. At present, the authority appointed around 48 security personnel. Of these 24 persons guard the monuments and destinations in and around Hampi. The HDA has plans to appoint more and more security personnel in the days to come. Due to the large inflow of tourists, the floodlights for every important monument in Hampi will be provided and attract the tourists even in nights. The floodlights are already fixed in Vijaya Vittala Temple at the time of Hampi festival which was held during Nov. 3-4, 2003.

Hampi Development Authority has taken necessary to satisfy the UNESCO about the two projects in Heritage Area ie., the Talwargatta Bridge and the Virupapurgadda footbridge. The authority's actions in fulfilling the conditions imposed by UNESCO are as under:

\section{(a) The Virupapuragadda Bridge:}

The construction of the footbridge was taken up by the Executive Engineer, PWD, Koppal out of MPLAD grants. Before the objections were raised by UNESCO the pylons of the bridge were already constructed on both sides of the river, but the pylons have been dismantled and removed. This is an important step taken by the authority to maintain the sanctum sanctorum at the heritage area.

\section{(b) The Talwargatta bridge:}

UNESCO had objected to the construction of a huge cable stayed bridge near the Talwargatta gate. Later Prof. Hans Detlef Kammier was sent as one man Commission to study and give recommendations in this regard. Based on the findings of his study, Govt. of Karnataka has approved the proposal of the construction of a bye-pass approach road and completion of the bridge.

\section{(c) Preparation of the site management plan:}

The Heritage Authority initiated the preparation of the site management plan. In connection with the actions were taken to procure the satellite map from ISRO and collect socio-economic and geographical data from the field. Finally, it was decided to entrust the work to an expert agency, viz., the Indian National Trust for Art and Cultural Heritage (INTACH), Bangalore. The materials collected so far including the internationally acclaimed site management plans have been handed over to INTACH. 


\section{Activities of the HDA}

Following are the main activities of Hampi Development Authority:

\section{Stoppage of Quarrying in the Heritage Area:}

The quarrying activities have been stopped in the Heritage area. On the request of the Heritage Authority, The Dept. of Mines and Geology, Govt. of Karnataka has passed the notification vide Cl-214-MMN-2002, Bangalore, dated 18/11/ 2002 banning the quarrying activities in the notified area. This is a positive sign of development.

\section{Providing road infrastructure:}

Roads have to be constructed under the Hampi project, out of the State Government funds and seven roads were identified for construction, of which three have already been completed at a cost of Rs. 2.45 crores. Two works have been included in the Bellary Package (phase) and a proposal has been submitted to the govt (PWD). It is requested that approval of the Government may be conveyed in respect of the proposed roads namely the Kamalapur-Talwargatta road (cost Rs. 49 lacs) and the Kaddiramapur gate - Hampi road (cost Rs. 62 lacs)

\section{Removal of Encroachments}

Recently the encroachments removal work has been taken up in front of the Gram Panchayat building, on the riverside, near the Manmata Konda and other places. A large number of encroachments made near the monuments have already been removed.

\section{Setting up of the Facilitation Centre.}

An extent of 10.71 acreas of land has been acquired through the KIADB by the state government to construct the facilitation by the CPWD out of the Govt of India grants. The CPWD has already floated the tender to initiate the construction.

\section{Signages:}

Modern Heritage Signages, designed by an expert agency are installed in the five places in Heritage area and the old ones are removed. The work is under progress at a faster rate. 


\section{Toilet complexes:}

For the convenience of tourists, four toilet complexes have been planned for construction at selected locations with all facilities in the Heritage area. Three of these are nearing completion.

\section{Circulation Plan:}

The Hampi Authority has prepared the circulation plan for the movement of vehicles in the Heritage Area and the same has been sent to the Dept. of Tourism, Government of India for final approval by the experts selected by the Department.

\section{Development of Lawns:}

It is not uncommon for the encroachments to re-appear after removal. As a preventive measure, the fencing and development of lawns are being taken up at selected locations seriously. Further this step will help in enhancing the aesthetics of the area and ensure cleanliness. At present the Heritage Authority along with Archaeological Survey of India is developing lawns at five important and central locations.

\section{Jungle Clearance:}

Jungle clearance and drainage works have been undertaken on war footing at certain places for ensuring the cleanliness and safety to the monuments and also to enhance the beauty of the surroundings.

\section{Services of a Security Agency:}

The services of a Security agency have been hired after following the tender process to maintain security in the area and safety of the monuments. The primary job of the agency is to ensure that unauthorized constructions and encroachments do not come up in the Heritage Area.

\section{Cleaning and Sanitation:}

The services of an agency have been employed through the tender process in order to maintain cleanliness and sanitation in the heritage Area especially in the Hampi village.

\section{Camouflaging:}

Some of the awkward structures like drinking water pump house, cisterns etc. are being removed or camouflaged in the heart of the Heritage Area to enhance the heritage of this tourist centre. 


\section{Archaeological Survey of India (ASI) in Action:}

The heritage project approved by Govt. of India includes the works to be taken up by the states as well as the Central government agencies. In the process, the Archaeological Survey of India is also flowed with the funds for carrying out excavations, conservation and development works. Some of the important works taken up by the ASI are as follows:

\section{Acquisition of Land:}

ASI is in the process of preparing proposals for acquiring land falling within 800 mtrs radius around the notified monuments.

\section{Excavations:}

The excavations have been taken up at important locations including the one at Vijaya Vittala Temple and the underground temple.

\section{Optical Fibre Lighting:}

The work of lighting the ceilings and interiors of Sasivekalu Ganesh, Kadakekalu Ganesh and the portico of Virupaksha temple has already been sanctioned.

\section{Illumination of Vijaya Vittala Temple:}

ASI has taken the work of external illumination of the Vijaya Vittala temple to the CPWD also.

\section{HDA in Tourism Development - Discussion, Findings and Suggestions}

The empirical evidences gathered by the authors on the topic produce the following discussion and findings.

(i) The Hampi Development Authority has played a very crucial role for the development of Hampi as a wonderful destination in Karnataka. In this regard Hampi Development Authority has taken certain measures to improve the areas in and around Hampi. The Authority closely monitors the infrastructural development in the area to attract more and more number of tourists. The developments of these facilities are a sine que non for recognition of Hampi as a world class destination. The Authority has undertaken developmental works like roads, footage, fencing, sanitation facilities etc. around the Hampi monuments. 
(ii) The data amply demonstrates that HDA strives for the development of tourism in Hampi and plans to organize training programmes to personnel to overcome the inconvenience to tourists at Hampi. Thus, the authority plays a strategic role in promoting tourism.

(iii) At present Hampi Development Authority is functioning well with the support of both the Central and State Governments. It has a separate legal existence too.

(iv) HDA has successfully regulated the traffic and vehicle movements in the temple area, of course the government vehicles are allowed with some exceptions. This measure is taken with no compromise on the beauty of the shrine.

(v) Hampi Development Authority is functioning with adequate confidence of the other concerned departments and incessant cooperation and help from the local community. The Authority has also prepared the site management plan.

(vi) The guidelines and suggestions given by the UNESCO has been meticulously followed to maintain the sustainability in and around Hampi. Its suggestions are mainly based on the security of the monuments from unusual situations.

Based on the suggestions given by the UNESCO to the Government of Karnataka, the Hampi Development Authority has taken the following measures:

(a) The Pylons of Virupapura Bridge is dismantled and removed

(b) Approved the proposal of the construction of a bypass approach road and completion of the Talwargatta Bridge.

(vii) It is evident from the dialogue by the authors with the authorities that the major sources of funds are from the Central and State Governments which in turn are used for removal of encroachments, construction of facilitation centre, toilet complexes and jungle clearances etc.

(viii) The ASI also has played a key role in some developmental works in and around Hampi from its own source of funds.

(ix) Hampi received a large number of visitors from India and abroad. Most of the foreign visitors are from Middle East, Germany, Australia and Russia etc. The main purpose of their visit is to study the Indian culture, art and architecture, traditions and also to see keenly the monuments at Hampi. It 
is known that during their stay, they also expect some sort of recreational facilities in Hampi. Generally, more number of foreign visitors to Hampi arrive in the months of December and January every year. Of course, Hampi attracts a large number of domestic visitors as well.

\section{Suggestion}

In order to mitigate the obstacles to tourism development, the authors have made the following suggestions to the Hampi Development Authority.

1. The HDA has to extensively utilize the expertise of ISRO and INTACH to prepare Satellite Map and to collect socio-economic, cultural and geographical data of the area. We opine that the area of Hampi is being developed for tourism and the local community should be involved in the planning process and the strict enforcement of rules should be there in order to avoid the unplanned development which destroys the nature and traditional culture.

2. The HDA's work is commendable since it has taken certain steps to stop unauthorized quarrying at the Heritage Area to protect the monuments and the road infrastructure is developed in the area using State Government Funds. This is not enough. The HDA should keep a constant vigil to prevent encroachments in future at the site.

3. The HDA has already taken necessary steps to set up Facilitation Centre for tourists. It will have interactive computers to provide information about the monument areas and historical spots to tourists in Hampi.

4. It is felt that the HDA appoint more number of qualified and trained people to add value to the service provided. The professionally qualified people are more useful in the execution of developmental plans. This is expected to trigger a faster rate of growth in the tourism sector in the state.

5. The HDA has already shown lot of interest in developing infrastructure like signages, toilet complexes etc. The study reveals us that the effective infrastructure management is the need of the hour.

6. The cleanliness and pollution control measures by HDA at the site must be given top priority. The frequency of the buses from Hospet should be enhanced.

7. Keeping in view of growing tourism which upholds our tradition, culture, values, life styles etc., the HDA should keep a watch and control the 
movements of hippies and other foreigners with the help of tourist police of the state government.

8. The HDA and the government should materialize tourist policy encouraging private sector participation wherever possible and necessary. This certainly boosts tourism.

9. The forest department should be allowed to play a positive and developmental role: They can increase the planting of trees, wayside facilities to tourists and make area greenery. This department may be an important stakeholder in the tourism sector in the days to come.

10. Since Hampi is situated on rocky mountains and the monuments are scattered over $24 \mathrm{sq}$. kms, the tourists are facing lot of difficulties to have access from one place to another. Therefore, Hampi Development Authority should take necessary steps to introduce the footage system throughout this area.

\section{Conclusion}

In conclusion it can be well stated that the HDA should function as a 'Watch Dog' to protect the World Heritage Status of Hampi. It should work for the protection of monuments and environment and the tourism activities should be within the carrying capacity. Hampi Development Authority should ensure the sustainable tourism. The Authority should ensure the proper and adequate conservation and preservation of all archaeological and historical monuments. It is worthy to note the statement made by the great poet, Kuvempu who said "Bariya Kallallavi Shileyu, Kaleya Baleyu." For this great son of this soil "Hampi is not a place surrounded by stones. It is the wonder of cultures".

Hence, the above discussion amply demonstrates that the HDA has greater responsibility in projecting this world heritage site as a world class tourist destination in the World Tourism Map. The authority has done better so far, and is expected to the best in future. 